arguments (in which the limited distribution of the radio-elements is deduced from the earth's temperature-gradient) is made the basis of a revival of Arrhenius's view that radio-active disintegration may be inhibited under the conditions prevailing at great depths (Nature, June 26, July io, and July 17 ). Thus, in place of the deduction that the amounts of uranium and thorium existing in the earth's interior are negligible, even thermally negligible, is put forward the alternative deduction that these parent elements are not necessarily absent, but only temporarily impotent, their output of energy, by which alone we could be aware of them, being inhibited by the enormous pressures to which they are subjected.

The latter alternative is favoured by the philosophic conception embodied in Le Chatelier's law of reaction, viz. that the internal reactions within a material system are such as will tend to oppose any external influences by which its equilibrium may be disturbed. It would at once be deduced from this "law" that radio-active transformations, implying as they do an immense output of energy in the form of electronic and atomic bombardments, must be inhibited by the application of sufficiently high pressure and temperature. Under high pressures the internal reactions will tend to oppose the pressure and therefore an increase of volume, and similarly under high temperatures the internal reactions will tend against a further rise of temperature. The internal reaction is favoured which results in the absorption of energy from an external source. Hence, radio-active changes, involving increase of volume and rise of temperature, would presumably be opposed by the physical conditions of the earth's deep interior.

As yet, however, we are unable to assert whether this deduction may safely be made to the extent of assuming inhibition. Frankly, it is a step taken in the dark. The law of reaction is known to be a useful guide as regards the tendency of molecular activities; its extension to include the internal activities of atoms has yet to be demonstrated. The evidence from direct experiment is manifestly insufficient, but so far as it goes it betrays on the part of the radio-elements an astonishing disregard for all external influences. For the present, then, the problem stands unsolved, as indeed it must remain until we know more of the internal mechanism of the radio-active atom.

However, whether one favours radio-active inhibition or independence, the remaining arguments in support of a crustal concentration of radium stand unaffected. The highest concentration of the radioelements is found in the acid rocks, which contain six times as much radium as the ultra-basic rocks. That is to say, the lighter rocks in their capacity as solvents are capable of carrying a higher proportion of the radio-elements than are the heavier rocks. It is for this reason that uranium, which is the heaviest element of all, has not gravitated to the earth's metallic core, as Dr. Schiller considers would be most probable. Further, there is clearly a marked antipathy between the radio-elements and native iron, for in all the terrestrial examples of the latter which have been examined, uranium and thorium are barely detectable. Correlating these facts with the earth's trizonal structure, we should expect an internal metallic core free, or nearly so, from the radioelements, an intermediate zone originally poor in, and now almost devoid of, these elements, and an outer crust more richly endowed, its wealth of radium, like its wealth of silica (and perhaps of many of the metallic ores), having accumulated in the course of the earth's evolution at the expense of the more sparsely distributed internal stores.

On the parallel drawn by Daubrée and extended by
Suess between iron meteorites and the earth's metallic core and between stony meteorites and the earth's intermediate ultra-basic zone, this conception receives still more convincing evidence. The stony meteorites are even more poverty-stricken in radium than the ultra-basic rocks, and the iron meteorites contain no radium whatever.

Imperial College, London, S.W., July 18.

\section{Area of Earth's Surface Visible at any Altitude.}

$I_{N}$ these days of aviators and of record heights attained by them, perhaps the following rule to find the area of the earth's surface visible from a given height may be of interest. The rule depends upon the fact that if the height above a sphere is $\frac{\mathrm{I}}{x}$ th part of the sphere's diameter, then the area visible from this height is $\frac{I}{x+2}$ th part of the sphere's total area. This admits of an easy geometrical proof.

Rule.-Express the height above the earth's surface as a fraction of the earth's diameter; multiply the rumerator of this fraction by 2 , and add the result to the denominator, then the resulting fraction gives the fraction of the earth's surface visible.

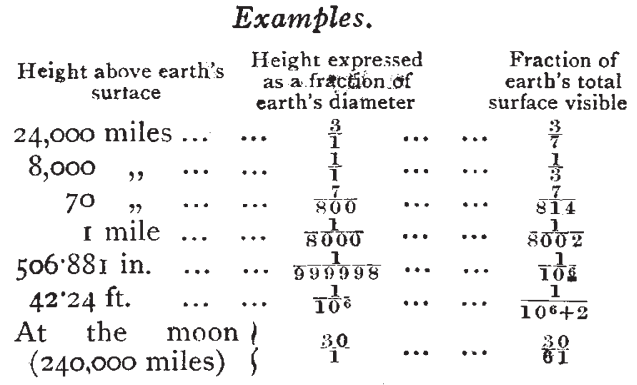

Of course, the effects of refraction are neglected; otherwise the rule is strictly accurate.

Municipal Secondary School, Bolton.

W. Moss,

\section{Submerged Valleys and Barrier Reefs.}

As I have never visited the Pacific Islands, I do not attempt to bring their valleys under the same category as those of the coast of the Red Sea and East Africa. Darwin's theory having been so often held to apply to all barrier reefs, it seemed to me interesting to refer to cases to which that theory does not apply, though superficially resembling that cited by Prof. Davis (Nature, February 6 and June 26).

I wished also to emphasise the resemblance between fault and subaërial erosion valleys, and in spite of Prof. Davis's assertion that they can be distinguished readily $I$ think we need definite assurance that those he cites are without doubt of the latter kind. Given that assurance, Dana's proof of Darwin's theory holds true for that case, but not universally wherever barriers (and atolls) are found. I myself took it for granted that those of Pemba and British East Africa were due to erosion by streams and tides alone, until I compared the better preserved examples of this almost rainless climate. Cyril Crossland.

NO. 2284, VOL. 9I] 